\title{
The maternal endocrine environment in the low-protein model of intra-uterine growth restriction
}

\author{
D. S. Fernandez-Twinn ${ }^{1 \star}$, S. E. Ozanne ${ }^{1}$, S. Ekizoglou ${ }^{1}$, C. Doherty ${ }^{1}$, L. James ${ }^{1}$, B. Gusterson ${ }^{2}$ \\ and C. N. Hales ${ }^{1}$ \\ ${ }^{1}$ Department of Clinical Biochemistry, University of Cambridge, Addenbrookes Hospital, Hills Road, \\ Cambridge CB2 2QR, UK \\ ${ }^{2}$ Department of Pathology, Western Infirmary, University of Glasgow, Glasgow G11 6NT, Scotland, UK
}

(Received 18 September 2002 - Revised 21 May 2003 - Accepted 23 June 2003)

\begin{abstract}
Many adult diseases, including type 2 diabetes, hypertension and cardiovascular disease, are related to low birth weight. The mechanistic basis of this relationship is not known. To investigate the role of fetal undernutrition, we used a rat model of maternal protein restriction in which dams were fed a diet containing $80 \mathrm{~g}$ protein $/ \mathrm{kg}(v .200 \mathrm{~g} / \mathrm{kg}$ in the control group) throughout gestation and lactation. Offspring were born smaller than controls and in adulthood developed diabetes, hyperinsulinaemia and tissue insulin resistance. To determine possible mechanisms of fetal programming, circulating levels of several hormones were measured in maternal plasma at gestational days 14,17 and 21 and fetal plasma at gestational day 21. Several differences were noted at day 14, when glucose concentrations in maternal and feto-placental blood were raised significantly $(P=0.04$ and $P=0.0001$ respectively); insulin levels in the low-protein (LP) dams were raised $(P=0.04)$, prolactin levels were raised $(P=0.047)$ and progesterone levels were reduced $(P=0 \cdot 02)$. Circulating $17 \beta$-oestradiol in the LP dams was raised by $35 \%$ over those of the controls from day 17 to day $21(P=0.008)$. A significant decrease in maternal leptin levels $(P=0.004)$ was observed at gestation on day 21. Neither oestradiol nor leptin levels were altered in the fetal circulation at day 21. Maternal and fetal corticosterone levels were comparable with control levels, suggesting that they do not initiate the programming effects in this model. Our present results suggest that maternal protein restriction imposes changes in maternal levels of glucose, insulin, prolactin, progesterone, oestradiol and leptin; these changes could influence the programming of eventual adult disease in the developing fetus.
\end{abstract}

Fetal programming: Intra-uterine growth restriction

A growing number of epidemiological studies reveal strong statistical links between poor fetal growth and subsequent development of type 2 diabetes in adulthood. In the first of these studies, Hales et al. (1991) found that among men in the Hertfordshire (UK) area, those who had lower birth weights and weights at 1 year were more likely to develop poor glucose tolerance and type 2 diabetes in later years. Other studies (for review, see Hales \& Barker, 2001) further reiterated the relevance of these findings. The mechanistic basis of this relationship is not known; however, various animal models have demonstrated a relationship between poor intra-uterine growth, loss of glucose tolerance and diabetes (for review, see Ozanne, 2001). It has therefore become a matter of great importance to identify the factors that programme the trajectory of fetal growth, and also the factors that have an impact on the transfer of nutrients and $\mathrm{O}_{2}$ across the materno-placental barrier to the developing fetus in situations where nutrient availability is limited.

There are a number of factors that are thought to have programming effects. Studies in rats and sheep have shown that glucose is the major substrate crossing the placenta, and its transfer is mediated by the placental glucose transporter (GLUT) 3. This is followed by amino acids, whereas non-esterified fatty acids (NEFA) cross the placenta in a smaller proportion, followed by glycerol. In early gestation, embryonic and fetal lipids are derived from maternal NEFA crossing the placenta, whereas in advanced gestation there is a gradual shift to de novo synthesis in fetal tissue (for review, see Herrera, 2002). We therefore measured most of these variables in maternal and fetal circulation to determine if differential nutrient partitioning might exert programming effects; we did not measure amino acids as the work of others has already identified taurine deficiency as a major feature of the protein-restricted model (Cherif et al. 1998).

There is evidence to suggest that low birth weight is associated with an increased activity of the adrenal, as demonstrated by higher plasma cortisol levels in adults (Clark, 1998; Phillips et al. 1998). It has been suggested that there is a variation in placental $11 \beta$-hydroxysteroid dehydrogenase type 2 in both rats and human subjects and that this enzyme activity correlates with birth weight, such that reduced activity of feto-placental $11 \beta$-hydroxysteroid 
dehydrogenase type 2 in the rat is associated with reduced birth weight and produces hypertensive and hyperglycaemic adult offspring (Seckl, 1997).

In the total energy restriction model, in which the food intake of the mother is restricted to $50 \%$ of her daily ad libitum intake in the last week of pregnancy, both the maternal and fetal corticosterone levels were increased. The fetuses were growth retarded and showed reduced pancreatic insulin content (Blondeau et al. 2001), suggesting a negative correlation between maternal glucocorticoids and fetal $\beta$-cell mass.

In vitro studies with rat embryos suggest that maternally derived prolactin has effects on the embryo during organogenesis (Karabulut et al. 1999). Since prolactin receptors are detectable in the embryo from conception (for review, see Symonds et al. 2001), alterations in the maternal hormonal environment may therefore affect placental growth early in gestation and regulation of fetal adipose tissue growth later in gestation.

Epidemiological studies have shown a significant relationship between cord blood leptin levels and birth weight (Cinaz et al. 1999; Christou et al. 2001). Cord blood leptin and intra-uterine growth were also related (Varvarigou et al. 1999) independently of other variables including insulin, components of the insulin-like growth factor system, placental weight and maternal leptin. It therefore represents an independent predictor of fetal growth (Hassink et al. 1997).

Oestrogen is a major pregnancy hormone derived mainly from the ovaries; however, later in gestation, the placenta takes over as the primary source of oestrogen in maternal circulation. Oestrogen is thought to cross the placenta by passive diffusion. The oestrogen analogue diethylstilbestrol has been shown to transfer to the fetus across the placenta (Miller et al. 1982). As maternal oestrogen has been shown to correlate positively with birth weight (Kaijser et al. 2000), we expected to see alterations in maternal circulation.

The primary aim of this project was, therefore, to determine the endocrine factors in both mother and fetus that are altered in the low-protein (LP) model of intra-uterine growth restriction, since these represent early indicators of putative programming influences and are most amenable to investigation. We specifically looked for changes in the peripheral circulating hormones of the protein-restricted dams compared with controls in the last week of pregnancy and in the fetal circulation of the two groups at day 21 , the day before parturition.

\section{Materials and methods}

\section{Animals and diets}

All procedures involving animals were carried out under the British Home Office Animals (Scientific Procedures) Act, 1986. Virgin female Wistar rats weighing $240-260 \mathrm{~g}$ were housed individually and maintained at $22^{\circ} \mathrm{C}$ on a $12 \mathrm{~h}$ light-dark cycle. They were mated and day 1 of gestation was taken as the day on which vaginal plugs were expelled. The pregnant dams were then randomised into two dietary groups, control and LP, fed ad libitum and weighed daily. The control group received a $200 \mathrm{~g}$ protein $/ \mathrm{kg}$ diet and the LP group received an isoenergetic $80 \mathrm{~g}$ protein $/ \mathrm{kg}$ diet (as described by Snoeck et al. (1990)) throughout gestation.

\section{Sample and data collection}

Between 09.00 and 10.00 hours, fed pregnant rats were exsanguinated under general anaesthesia and the blood collected into an EDTA-containing syringe. On each occasion, the dam was confirmed as being pregnant and the number of fetuses counted. Pregnancies resulting in less than ten or more than sixteen fetuses were excluded from the study in order to minimise the confounding effects due to differences in nutrition relating to litter size. There was no difference in litter sizes due to dietary restriction. Whole blood was centrifuged at $1600 \mathrm{~g}$ for $10 \mathrm{~min}$ at $4^{\circ} \mathrm{C}$ and the plasma saved into portions, which were then flash frozen in liquid $\mathrm{N}_{2}$ and stored at $-80^{\circ} \mathrm{C}$ for later analysis of hormone concentrations. In addition, after the dams were killed at day 21 of gestation, fetal blood was collected by decapitation while placentas were still attached. The blood from each litter was pooled to facilitate the measurement of a maximum number of hormones and endocrine factors. Fetal body weights and placental weights at days 18 and 21 were therefore obtained from a separate group of experimental and control dams. Following clotting, serum was obtained by centrifugation at $3000 \mathrm{~g}$ for $3 \mathrm{~min}$ in a microcentrifuge at room temperature, flash frozen in liquid $\mathrm{N}_{2}$ and stored at $-80^{\circ} \mathrm{C}$.

The total pancreatic insulin content of pregnant dams on day 14 was measured by extraction of $50 \mathrm{mg}$ whole pancreas into $0.5 \mathrm{ml}$ acid-ethanol solution $(75 \mathrm{ml}$ ethanol $(950 \mathrm{ml} / \mathrm{l}), 23.5 \mathrm{ml}$ distilled $\mathrm{H}_{2} \mathrm{O}, 1.5 \mathrm{ml} \mathrm{HCl}(370 \mathrm{~g} / \mathrm{l})$ ). The tissue was chopped into homogenous pieces and the samples sonicated for $1 \mathrm{~min}$ and then stored at $4^{\circ} \mathrm{C}$ overnight. The next day, the sample was centrifuged at $800 \mathrm{~g}$ for $15 \mathrm{~min}$. The supernatant fractions containing the released insulin were then removed to a fresh tube, flash frozen in liquid $\mathrm{N}_{2}$ and stored at $-80^{\circ} \mathrm{C}$ until assayed. The total insulin content was then expressed as $\mathrm{nmol} / \mathrm{mg}$ pancreas. Data on maternal body weights and food intake data were also collected.

Maternal blood at 14, 17 and 21 days of gestation and fetal blood at day 21 was analysed for glucose, insulin, triacylglycerol, NEFA, leptin, prolactin, corticosterone, progesterone and oestradiol.

\section{Glucose measurements}

Maternal plasma glucose and fetal plasma glucose were measured on a Dimension auto-analyser RxL-HM (Dade Behring, Marburg, Germany) with a kit from Roche Diagnostics (Roche Diagnostics GmbH, Mannheim, Germany). Glucose in feto-placental blood from pregnancies on day 14 was determined using a glucose meter (Hemocue, Sheffield, UK).

\section{Hormone and fatty acid assays}

All samples were assayed in duplicate and an intra-assay CV $\leq 5 \%$ was accepted. Insulin was measured by immunoassay 
using a double-antibody ultra-sensitive rat insulin ELISA kit (Mercodia, Uppsala, Sweden). Triacylglycerol was measured on the Cobas Mira automated chemistry analyser (Roche Diagnostics Corporation, Indianapolis, IN, USA) with intra-batch CV from quality control serum in analytical runs of $2.5 \%$. Lipid and glucose determinations were done as part of routine assays carried out at Addenbrookes Hospital (Cambridge, UK) using kits from Roche Diagnostics GmbH. A leptin radioimmunoassay kit from Linco Research (Biogenesis, Poole, Dorset, UK) was used to determine leptin levels in plasma. Prolactin levels in plasma were determined using a rat prolactin enzyme immunoassay from SPI-BIO (Immuno Diagnostic Systems, Boldon, Tyne \& Wear, UK). Corticosterone measurements were made using a radioimmunoassay kit from Immuno Diagnostic Systems. Progesterone was measured using a progesterone radioimmunoassay kit supplied by Diagnostic Systems Laboratories Inc. (Webster, TX, USA). Levels of $17 \beta$-oestradiol were measured using an ELISA-based assay from R\&D Systems Europe Ltd (Abingdon, Oxon., UK). All assays were performed according to the manufacturers' protocols.

\section{Statistical analysis}

All statistical calculations were carried out using Statistica for Mac (StatSoft Inc., Tulsa, OK, USA). The significance of any difference between groups was then examined by Mann-Whitney non-parametric analysis. Results in all cases are given as mean values with their standard errors, together with the absolute probability $(P)$ values where appropriate.

\section{Results}

\section{Weight gain and food intake}

The body weights of the two groups were equivalent at the start of pregnancy and both groups gained weight daily; however, the LP group gained less weight than the controls and significantly so from day 14 onwards (Fig. $1 ; P=0.028$ at day $14, P=0.001$ at day 21$)$.

Food intake was initially very similar: both groups consumed 20-25 g of their respective diets per d. Between days 14 and 17, however, the LP dams were consuming significantly more diet both in absolute terms and as \% body weight (Table 1). Peak food intake in both groups was observed at day 17, after which consumption gradually decreased to reach lowest levels the day before birth (day 21).

\section{Litter sizes}

There were no significant differences in litter sizes between both groups at either day 18 or 21 of gestation (Table 2). The number of resorption sites was also not different between groups, with most litters having no resorption sites or only one.

\section{Body weights and placental weights}

Fetal body weights were significantly lower in the LP group compared with controls at both days 18 and 21 of gestation

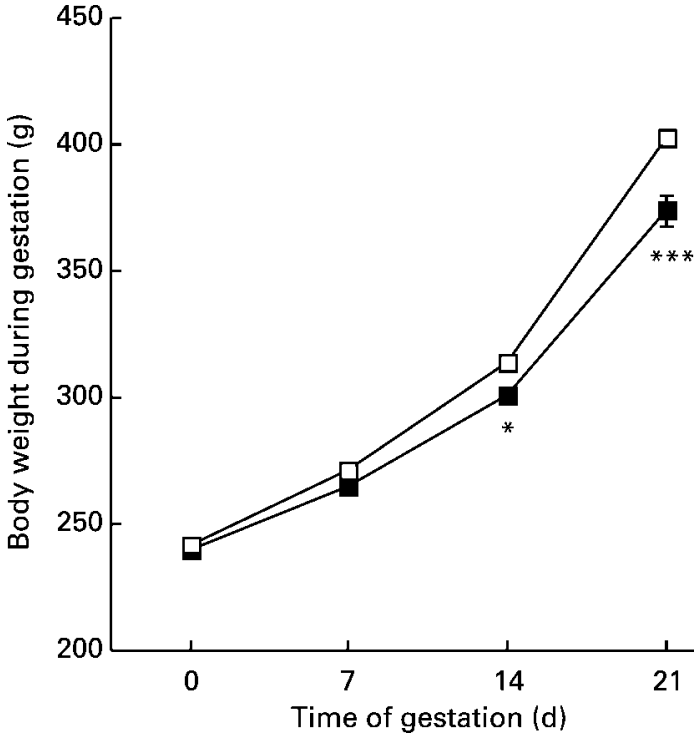

Fig. 1. Effect of diets containing either $200 \mathrm{~g}$ protein (control, $\mathbf{a}$ ) or $80 \mathrm{~g}$ protein (low protein, $\square$ ) $/ \mathrm{kg}$ during pregnancy on the body weight of dams. For details of diets and procedures, see p. 816 . Values are means with their standard errors shown by vertical bars (eight per group). Mean values were significantly different from control values at the same time point: ${ }^{\star} P=0.028,{ }^{\star \star \star} P=0.001$.

(Table 2). The placental weights of the LP fetuses were significantly lower than those of the controls at both days 18 and 21 of gestation (Table 3). The placenta:body weight ratios were not different between the two groups at day 18 of gestation. However, at day 21, the ratio was significantly lower in the LP fetuses compared with that of the controls. Between days 18 and 21, the placental weights of the LP group increased in weight by $30 \%$, but the weights in the control group increased by $39 \%$.

\section{Glucose and insulin}

Fed plasma glucose levels in maternal peripheral circulation of LP dams were raised significantly on day 14 of gestation. Levels then dropped from day 17 onwards to reach their lowest levels at day 21: this was comparable with the control levels (Table 4).

Fetal plasma glucose levels at day 21, however, like maternal levels at this time point, did not differ between the control and LP groups (3.8 (SEM 0.34) v. 3.6 (SEM $0.58) \mathrm{mmol} / \mathrm{l}$ respectively (Table 6)).

Plasma insulin levels at day 14 of gestation were also significantly raised in the circulation of the LP dams compared with the controls (Table 4). Total insulin content in the maternal pancreata at day 14 was also raised in the LP dams (Table 4). Maternal plasma levels at other time points were, however, comparable between the two groups. Fetal insulin of the LP fetuses at day 14 was found to be significantly higher than that of the control group, although at day 21 it was not different from the control group (see Table 6).

\section{Triacyglycerol and non-esterified fatty acids}

The maternal levels of triacylglycerol and NEFA increased in both control and LP dams towards the end 
Table 1. Effect of a control ( $200 \mathrm{~g}$ protein $/ \mathrm{kg})$ or low-protein $(80 \mathrm{~g} / \mathrm{kg})$ diet on the food intake of rat dams during gestationt

(Mean values with their standard errors for eight dams per group)

\begin{tabular}{|c|c|c|c|c|c|c|c|c|}
\hline \multirow[b]{4}{*}{ Time of gestation $(\mathrm{d})$} & \multicolumn{8}{|c|}{ Food intake } \\
\hline & \multicolumn{4}{|c|}{ g } & \multicolumn{4}{|c|}{$\%$ Body weight } \\
\hline & \multicolumn{2}{|c|}{ Control } & \multicolumn{2}{|c|}{ LP } & \multicolumn{2}{|c|}{ Control } & \multicolumn{2}{|c|}{ LP } \\
\hline & Mean & SEM & Mean & SEM & Mean & SEM & Mean & SEM \\
\hline 3 & $20 \cdot 7$ & 1.55 & $24 \cdot 1$ & 1.62 & 8.2 & 0.53 & $9 \cdot 7^{*}$ & 0.52 \\
\hline 6 & 23.4 & 1.56 & 24.6 & 1.81 & 8.5 & 0.42 & $9 \cdot 2$ & 0.52 \\
\hline 9 & $24 \cdot 7$ & $2 \cdot 18$ & 25.4 & 1.54 & 8.7 & 0.67 & 9.0 & 0.43 \\
\hline 14 & 23.4 & 0.63 & $25 \cdot 7^{\star}$ & 1.06 & 7.5 & 0.17 & $8 \cdot 4^{\star \star}$ & 0.24 \\
\hline 17 & $25 \cdot 8$ & 1.52 & $28 \cdot 7^{\star}$ & 0.87 & $7 \cdot 6$ & 0.33 & $8 \cdot 8^{*}$ & 0.36 \\
\hline 20 & $23 \cdot 3$ & 1.22 & $25 \cdot 8$ & 1.48 & $6 \cdot 0$ & 0.34 & $7 \cdot 1^{*}$ & 0.4 \\
\hline 21 & 20.4 & 1.59 & 20.5 & 2.44 & 5.0 & 0.29 & $6 \cdot 0^{*}$ & 0.48 \\
\hline
\end{tabular}

LP, low protein.

Mean values were significantly different from control values at the same time point: ${ }^{\star} P<0.05,{ }^{\star \star} P<0.01$

†For details of diets and procedures, see p. 816.

of pregnancy; however, this increase was greater in the LP group (Table 5).

\section{Leptin}

Leptin levels in LP dams were comparable with control levels at day 14. The control dams had increased leptin levels at day 17 (Table 5), which had the effect of reducing food intake in this group thereafter (Table 1; days 20 and 21). The LP leptin levels at day 21, however, were significantly lower than the control values (Table 5) and were accompanied by a greater food intake as a percentage of body weight compared with the control group at the later time points. There were no significant differences in fetal levels at day 21 (Table 6).

\section{Prolactin}

Prolactin levels were raised significantly in the LP dams at day 14 of gestation compared with the controls (Table 5). Levels at later time points were comparable with controls. Day 21 fetal plasma levels were also comparable in the two groups (Table 6).

Table 2. Effect of a control $(200 \mathrm{~g}$ protein $/ \mathrm{kg}$ ) or low-protein $(80 \mathrm{~g}$ protein $/ \mathrm{kg})$ diet on litter size and fetal body weight at days 18 and 21 of gestationt

(Mean values with their standard errors)

\begin{tabular}{|c|c|c|c|c|c|c|c|c|c|c|c|c|}
\hline \multirow[b]{3}{*}{ Time of gestation $(d)$} & \multicolumn{6}{|c|}{ Litter size $(n)$} & \multicolumn{6}{|c|}{ Fetal body weight (g) } \\
\hline & \multicolumn{3}{|c|}{ Control } & \multicolumn{3}{|c|}{ LP } & \multicolumn{3}{|c|}{ Control } & \multicolumn{3}{|c|}{ LP } \\
\hline & Mean & SEM & $n$ & Mean & SEM & $n$ & Mean & SEM & $n$ & Mean & SEM & $n$ \\
\hline 18 & 15 & 2 & 8 & 15 & 3 & 8 & 0.88 & 0.20 & 106 & $0.83^{\star \star}$ & 0.10 & 107 \\
\hline 21 & 13 & 3 & 8 & 14 & 2 & 8 & 3.98 & 0.35 & 53 & $3 \cdot 72^{\star \star \star}$ & 0.28 & 41 \\
\hline
\end{tabular}

LP, low protein.

Mean values were significantly different from control values at the same time point: ${ }^{\star \star} P<0.01,{ }^{\star * \star} P<0.001$.

†For details of diets and procedures, see p. 816.

Table 3. Effect of a control $(200 \mathrm{~g}$ protein $/ \mathrm{kg})$ or low-protein $(80 \mathrm{~g}$ protein $/ \mathrm{kg})$ diet on placental weight and placenta:body weight ratio at days 18 and 21 of gestation $\dagger$

(Mean values with their standard errors)

\begin{tabular}{|c|c|c|c|c|c|c|c|}
\hline \multirow[b]{2}{*}{ Time of gestation (d) } & & \multicolumn{3}{|c|}{ Control (g) } & \multicolumn{3}{|c|}{$\mathrm{LP}(\mathrm{g})$} \\
\hline & & Mean & SEM & $n$ & Mean & SEM & $n$ \\
\hline \multirow[t]{2}{*}{18} & Placental weight & 0.32 & 0.06 & 106 & $0.29^{* \star}$ & 0.05 & 107 \\
\hline & Placenta:BW ratio & 0.37 & 0.07 & 106 & 0.36 & 0.00 & 107 \\
\hline \multirow[t]{2}{*}{21} & Placental weight & 0.45 & 0.06 & 53 & $0.39^{\star \star \star}$ & 0.05 & 41 \\
\hline & Placenta:BW ratio & 0.113 & 0.015 & 53 & $0.105^{\star *}$ & 0.013 & 41 \\
\hline
\end{tabular}

LP, low protein; BW, body weight.

Mean values were significantly different from control values at the same time point: ${ }^{\star \star} P<0.01,{ }^{\star \star \star} P<0.001$.

†For details of diets and procedures, see p. 816. 


\section{Steroid and pregnancy hormones}

Control maternal plasma corticosterone levels ranged between 67.7 and $82.8 \mathrm{ng} / \mathrm{ml}$ during the last week of pregnancy and were not significantly different between the two groups at any of the time points studied (Table 5). Levels were also comparable in both groups of fetuses at day 21 (Table 6). Progesterone concentration in the LP dams was only significantly lower than in the controls at day 14 (Table 5). At other time points, both control and LP levels were comparable. Fetal progesterone levels at day 21 were generally much lower than maternal levels; however, no difference was observed between the two groups (Table 6). Although 17 $\beta$-oestradiol concentrations were significantly raised in the maternal circulation of LP dams at both day 17 and day 21 when compared with the controls (Table 5), the fetal levels at day 21 were comparable in the two groups.

\section{Discussion}

The LP mothers were hyperglycaemic at day 14 of pregnancy and this is accompanied by an increase in their circulating insulin levels. This is likely to be due to the increased carbohydrate content of the LP diet and also the dams' increased food intake in absolute terms and as $\%$ body weight. By day 21, the insulin:glucose ratios were increased in both groups, presumably to cope with the increased metabolic demands of pregnancy, and this is also a reflection of pregnancy-related insulin resistance. Herrera et al. (1985) have shown that placental glucose transfer increases linearly with maternal glycaemia and the actual transfer to the fetus is mainly dependent on the concentration of glucose in the maternal circulation. Since under hyperglycaemic conditions placental GLUT3 is overexpressed (Boileau et al. 1995), and conversely, a reduced maternal plasma glucose content results in a corresponding reduced placental GLUT3 expression (Lesage et al. 2002); this would be an interesting variable to measure in this model.

Using a model of intra-uterine growth restriction induced by maternal $50 \%$ food restriction, Blondeau et al. (2001) showed that corticosterone levels were raised both in the maternal and fetal circulation: this resulted directly in impaired fetal $\beta$-cell development, since the effect was reversed in food-restricted dams that had been adrenalectomised. There has, however, been much debate surrounding the hypothesis that similar elevated levels of glucocorticoids in utero are responsible for low birth weights in the LP model. To date, there has been no direct evidence of increased glucocorticoid levels in either the maternal or fetal circulation in the protein restriction model. Measurement of 11ß-hydroxysteroid dehydrogenase type 2 (Langley-Evans et al. 1996; Langley-Evans, 1997; Seckl, 1997) showed a reduction in the LP models, but fetal glucocorticoids were not measured: although growth retardation is preceded by raised plasma fetal corticosterone in the maternal food restriction model, it does not correlate with raised maternal corticosterone levels (Lesage et al. 2002). The present study shows that levels of corticosterone in both maternal and fetal circulation were unaffected by 
Table 5. Effect of a control ( $200 \mathrm{~g}$ protein $/ \mathrm{kg})$ or a low-protein $(80 \mathrm{~g}$ protein $/ \mathrm{kg})$ diet on plasma lipid and hormone concentrations in rat dams during gestation $\dagger$

(Mean values with their standard errors for eight dams per group)

\begin{tabular}{|c|c|c|c|c|c|c|c|c|c|c|c|c|}
\hline \multirow[t]{3}{*}{ Time of gestation $(d) \ldots$} & \multicolumn{4}{|c|}{14} & \multicolumn{4}{|c|}{17} & \multicolumn{4}{|c|}{21} \\
\hline & \multicolumn{2}{|c|}{ Control } & \multicolumn{2}{|c|}{ LP } & \multicolumn{2}{|c|}{ Control } & \multicolumn{2}{|c|}{ LP } & \multicolumn{2}{|c|}{ Control } & \multicolumn{2}{|c|}{ LP } \\
\hline & Mean & SEM & Mean & SEM & Mean & SEM & Mean & SEM & Mean & SEM & Mean & SEM \\
\hline Triacylglycerol (mmol/l) & 0.8 & 0.1 & 0.9 & 0.1 & $1 \cdot 3$ & 0.2 & $1 \cdot 2$ & 0.3 & 1.5 & 0.2 & $2 \cdot 0^{*}$ & 0.3 \\
\hline NEFA $(\mathrm{mmol} / \mathrm{l})$ & 114 & $37 \cdot 7$ & 80 & 13.9 & 154 & $43 \cdot 1$ & 205 & $68 \cdot 6$ & 332 & 33.8 & 430 & $72 \cdot 7$ \\
\hline Leptin (ng/ml) & 4.2 & 0.6 & 4.8 & 0.3 & 3.5 & 0.3 & 2.6 & 0.4 & $7 \cdot 1$ & 0.4 & $3 \cdot 4^{\star *}$ & 0.4 \\
\hline Prolactin (ng/ml) & $17 \cdot 0$ & 1.9 & $24 \cdot 0^{*}$ & 3.4 & $15 \cdot 0$ & 4.3 & 14.5 & 4.5 & $12 \cdot 7$ & $2 \cdot 2$ & 13.7 & 4.2 \\
\hline Corticosterone (ng/ml) & $71 \cdot 0$ & 4.0 & $82 \cdot 8$ & $7 \cdot 8$ & $72 \cdot 7$ & 3.9 & 70.9 & $5 \cdot 6$ & $70 \cdot 3$ & 4.4 & $67 \cdot 7$ & 6.9 \\
\hline Progesterone (ng/ml) & 164 & $14 \cdot 3$ & $125^{\star}$ & $6 \cdot 7$ & 156 & 5.4 & 155 & $7 \cdot 6$ & 102 & 18.4 & 87 & 11.8 \\
\hline Oestradiol (pg/ml) & 167 & 8.4 & 137 & 8.2 & 153 & $12 \cdot 4$ & $200^{\star *}$ & $12 \cdot 7$ & 188 & $9 \cdot 3$ & $226^{\star \star}$ & $12 \cdot 2$ \\
\hline
\end{tabular}

LP, low protein; NEFA, non-esterified fatty acid.

Mean values were significantly different from control values at the same time point: ${ }^{\star} P<0.05,{ }^{\star \star} P<0.01$

†For details of diets and procedures, see p. 816.

maternal protein restriction. This suggests that changes in glucocorticoid levels do not play a direct programming role in this model; however, the possibility that there are differences in fetal glucocorticoid receptor expression cannot be excluded at this stage.

All levels of pregnancy and lactogenic hormones in the control dams were found to be within the normal range, as reviewed by Nathanielsz (1978). Progesterone levels in normal rat pregnancy increase steadily throughout gestation and then fall rapidly in the last $5 \mathrm{~d}$ prior to parturition. In the LP dams, progesterone levels were attenuated at day 14, but were comparable with control values by day 17. The main effect of progesterone during pregnancy is to counter-regulate the effects of prolactin (Sorenson et al. 1993) and recent prolactin receptor knockout studies have identified a role for prolactin and/or its receptor in $\beta$-cell mass and insulin production (Freemark et al. 2002). We speculate, therefore, that the combined effects of decreased progesterone and increased prolactin in the maternal circulation at day 14 gestation would be enhanced maternal $\beta$-cell mass and insulin content, which is consistent with our present observations. However, as we have observed, the raised oestrogen levels in the LP dams later in gestation may counteract this transient hyperglycaemia and hyperinsulinaemia (Sorenson et al. 1993).

Rat maternal plasma leptin levels in early pregnancy are normally twofold that of the virgin rats. This has direct correlation with the increased amount of fat mass, since leptin is produced predominantly by adipose cells. In rodents and human subjects, serum leptin is further increased towards the end of pregnancy. These raised levels are, however, derived mainly from placental secretion of leptin into the maternal circulation (Lewandowski et al. 1999) (98\% of placental leptin is released into the maternal circulation and up to $2 \%$ is released into the fetal circulation; Linnemann et al. 2000); they are also regulated by the levels of hormones that stimulate leptin secretion, i.e. insulin, oestrogens and human chorionic gonadotrophin (Sivan et al. 1998). Consistent with this, the leptin levels in our present control dams were raised towards the end of pregnancy: this had the effect of reducing food intake in the last week of gestation. In contrast, leptin levels in the LP group did not rise at the end of pregnancy, perhaps because of reduced maternal fat stores or reduced placental weights. This effect is transmitted to the maternal milieu and is consistent with leptin acting

Table 6. Effect of a control $(200 \mathrm{~g}$ protein $/ \mathrm{kg})$ or a low-protein $(80 \mathrm{~g}$ protein $/ \mathrm{kg})$ diet on fetal plasma glucose at days 14 and 21 of gestation and fetal plasma hormone concentrations at day 21 of gestation $\dagger$ (Mean values with their standard errors for fetuses from eight dams per group)

\begin{tabular}{|c|c|c|c|c|c|}
\hline & \multicolumn{2}{|c|}{ Control } & \multicolumn{2}{|c|}{ LP } & \multirow[b]{2}{*}{ Statistical significance of effect: $P \neq$} \\
\hline & Mean & SEM & Mean & SEM & \\
\hline \multicolumn{6}{|l|}{ Glucose (mmol/l) } \\
\hline Day 14 & $2 \cdot 8$ & 0.16 & 5.9 & 0.22 & $<0.0001$ \\
\hline Day 21 & 3.8 & 0.34 & 3.6 & 0.58 & 0.73 \\
\hline Insulin (pmol/l) & 417 & 64 & 539 & 131 & 0.41 \\
\hline Leptin (ng/ml) & 2.7 & 0.42 & 3.4 & 0.18 & 0.12 \\
\hline Prolactin (ng/ml) & $1 \cdot 8$ & 0.15 & 1.6 & 0.17 & 0.4 \\
\hline Corticosterone (ng/ml) & $74 \cdot 0$ & $8 \cdot 22$ & $76 \cdot 8$ & 6.92 & 0.38 \\
\hline Progesterone (ng/ml) & $8 \cdot 9$ & 1.03 & $7 \cdot 6$ & 0.45 & 0.14 \\
\hline Oestradiol (pmol/l) & $142 \cdot 26$ & $22 \cdot 0$ & $143 \cdot 25$ & 21.5 & 0.18 \\
\hline
\end{tabular}

$\mathrm{LP}$, low protein.

†For details of diets and procedures, see p. 816.

$\ddagger$ Control $v$. LP values at the same time point. 
as a signal of energy status between mother and fetus (Hassink et al. 1997; Wauters et al. 2000). The feedback signal to the maternal hypothalamus is reduced satiety, which signals the LP dams to maintain food intake to increase fat stores, thereby ensuring adequate energy intake to sustain the offspring.

Both hypertriacylglycerolaemia and insulin resistance occur during pregnancy in human subjects (Montelongo et al. 1992; Alvarez et al. 1996) and rats (Martin-Hidalgo et al. 1994). Gestational hypertriacylglycerolaemia seems to be the result of enhanced production of triacylglycerol by the liver (Wasfi et al. 1980) and decreased clearance of circulating triacylglycerol; this is a consequence of reduced lipoprotein lipase activity in adipose tissue (Herrera et al. 1988; Martin-Hidalgo et al. 1994). As reviewed by Herrera (2002), maternal NEFA are an important source of longchain polyunsaturated fatty acids, as both term and preterm infants can synthesise long-chain polyunsaturated fatty acids from parental fatty acids. An excess of NEFA in maternal circulation as seen in the LP dams could, therefore, programme the previously reported reduction in hepatic $\Delta 5$ desaturase activity in the offspring (Ozanne et al. 1998).

It has become evident that the maternal milieu in a growth-restricted pregnancy is altered in many ways, and the present study has identified a number of molecules that may be involved in the programming events that alter the fetal metabolic phenotype. Cross-talk between the mother and fetus are clearly mediated by the placenta and if there exists a master programming molecule, it is most likely to be derived from the placenta acting as a nutrient sensor. The role of the placenta becomes more dominant with advancing gestation, supplying cues such as oestrogen and leptin.

In conclusion, we have identified several molecules that could potentially function as programming initiators for poor glucose tolerance, insulin resistance and the metabolic syndrome. These factors could act independently or in concert, although the sequence of events is still unclear. It will be interesting to determine the responsiveness of the offspring to the various endocrine signals we have identified, and we can do this by measuring receptor expression in the placenta and neonatal tissue, since it is likely these may act as indicators of the thrifty phenotype (metabolic syndrome).

\section{Acknowledgements}

We thank M. Dowsett for help with the initial oestradiol assays and staff at the Department of Clinical Biochemistry, Addenbrookes NHS Trust, Cambridge, for performing the glucose and lipid analyses. Expert technical assistance was provided by A. Wayman, A. Flack and D. Hutt. This study was supported by the NIH, USA, (grant no. AG2060802), the Parthenon Trust and the Wellcome Trust.

\section{References}

Alvarez JJ, Montelongo A, Iglesias A, Lasuncion MA \& Herrera E (1996) Longitudinal study on lipoprotein profile, high density lipoprotein subclass, and postheparin lipases during gestation in women. J Lipid Res 37, 299-308.

Boileau P, Mrejen C, Girard J \& Hauguel-de Mouzon S (1995) Overexpression of GLUT3 placental glucose transporter in diabetic rats. J Clin Invest 96, 309-317.

Blondeau B, Lesage J, Czernichow P, Dupouy JP \& Breant B (2001) Glucocorticoids impair fetal $\beta$-cell development in rats. Am J Physiol Endocrinol Metab 281, E592-E599.

Cherif H, Reusens B, Ahn MT, Hoet JJ \& Remacle C (1998) Effects of taurine on the insulin secretion of rat islets from dams fed a low-protein diet. $J$ Endocrinol 159, 341-348.

Christou H, Connors JM, Ziotopoulou M, et al. (2001) Cord blood leptin and insulin-like growth factor levels are independent predictors of fetal growth. J Clin Endocrinol Metab 86, 935-938.

Cinaz P, Sen E, Bodeci A, Ezgu FS, Atalay Y \& Koca E (1999) Plasma leptin levels of large for gestational age and small for gestational age infants. Acta Pediatr 88, 753-755.

Clark PM (1998) Programming of the hypothalamo-pituitaryadrenal axis and the fetal origins of adult disease hypothesis. Eur J Pediatr 157, Suppl. 1, S7-S10.

Freemark M, Avril I, Fleenor D, et al. (2002) Targeted deletion of the PRL receptor: Effects on islet development, insulin production, and glucose tolerance. Endocrinology 143, $1378-1385$.

Hales CN, Barker DJP, Clark PMS, Cox LJ, Fall C \& Winter PD (1991) Fetal and infant growth and impaired glucose tolerance at age 64 years. Br Med J 303, 1019-1022.

Hales CN \& Barker DJ (2001) The thrify phenotype hypothesis. Br Med Bull 60, 5-20.

Hassink SG, de Lancey E, Sheslow DV, et al. (1997) Placental leptin: an important new growth factor in intrauterine and neonatal development? Pediatrics 100, E1-E6.

Herrera E, Palacin M, Martin A \& Lasuncion MA (1985) Relationship between maternal and fetal fuels and placental glucose transfer in rats with maternal diabetes of varying severity. Diabetes 34, Suppl. 2, 42-46.

Herrera E, Lasuncion MA, Gomes Coronado D, Aranda P, LopezLuna P \& Maier I (1988) Role of lipoprotein lipase activity on lipoprotein metabolism and the fate of circulating triglycerides in pregnancy. Am J Obstet Gynecol 158, 1575-1583.

Herrera E (2002) Implications of dietary fatty acids during pregnancy on placental, fetal and postnatal development-A review. Placenta 23, Suppl. A, S9-S19.

Karabulut AK, Layfield R \& Pratten MK (1999) The mechanism of growth-promoting effects of prolactin in embryogenesislinks to growth factors. Cells Tissues Organs 164, 2-13.

Kaijser M, Granath F, Jacosen G, Cnattingius S \& Ekbom A (2000) Maternal pregnancy estriol levels in relation to anamnestic and fetal anthropometric data. Epidemiology 11, $315-319$.

Langley-Evans SC, Phillips GJ, Benediktsson R, et al. (1996) Protein intake in pregnancy, placental glucocorticoid metabolism and the programming of hypertension in the rat. Placenta 17, 169-172.

Langley-Evans SC (1997) Maternal carbenoxolone treatment lowers birthweight and induces hypertension in the offspring of rats fed a protein-replete diet. Clin Sci 93, 423-429.

Lesage J, Hahn D, Leonhardt M, Blondeau B, Breant B \& Dupouy JP (2002) Maternal undernutrition during late gestation-induced intrauterine growth restriction in the rat is associated with impaired placental GLUT3 expression, but does not correlate with endogenous corticosterone levels. $J$ Endocrinol 174, 37-43.

Lewandowski K, Horn R, O'Callaghan CR, et al. (1999) Free leptin, bound leptin, and soluble leptin receptor in normal and diabetic pregnancies. J Clin Endocrinol Metab 84, 2755-2758. 
Linnemann K, Malek A, Sager R, Blum WF, Schneider H \& Fusch C (2000) Leptin production and release in the dually in vitro perfused human placenta. J Clin Endocrinol Metab $\mathbf{8 5}, 4298-4301$.

Martin-Hidalgo A, Holm C, Belfrage P, Schotz MC \& Herrera E (1994) Lipoprotein lipase and hormone sensitive lipase activity and mRNA in adipose tissue during pregnancy. Am J Physiol 266, E930-E935.

Miller RK, Heckmann ME \& McKenzie RC (1982) Diethylstilbestrol: placental transfer, metabolism, covalent binding and fetal distribution in the Wistar rat. J Pharmacol Exp Ther 220, 358-365.

Montelongo A, Lasuncion MA, Pallardo LF \& Herrera E (1992) Longitudinal study of plasma lipoproteins and hormones during pregnancy in normal and diabetic women. Diabetes 41, $1651-1659$.

Nathanielsz PW (1978) Parturition in rodents. Semin Perinatol 2 , 223-234.

Ozanne SE, Martensz ND, Petry CJ, Loizou CL \& Hales CN (1998) Maternal low protein diet in rats programmes fatty acid desaturase activities in the offspring. Diabetologia 41, $1337-1342$.

Ozanne SE (2001) Metabolic programming in animals. Brit Med Bull 60, 143-152.

Phillips DIW, Barker DJP, Fall CHD, et al. (1998) Elevated plasma cortisol concentrations: a link between low birth weight and the insulin resistance syndrome? J Clin Endocrinol Metab 83, 757-760.
Seckl JR (1997) Glucocorticoids, feto-placental 11 beta-hydroxysteroid dehydrogenase type 2 , and the early life origins of adult disease. Steroids 62, 89-94.

Sivan E, Whittaker PG, Sinha D, et al. (1998) Leptin in human pregnancy: the relationship with gestational hormones. Am J Obstet Gynecol 179, 1128-1132.

Snoeck A, Remacle C, Reusens B \& Hoet JJ (1990) Effect of a low protein diet during pregnancy on the foetal rat endocrine pancreas. Biol Neonate 57, 107-118.

Sorenson RL, Brelje TC \& Roth C (1993) Effects of steroid and lactogenic hormones on islets of Langerhans: A new hypothesis for the role of pregnancy steroids in the adaptation of islets to pregnancy. Endocrinology 133, 2227-2234.

Symonds ME, Budge H, Stephenson T \& McMillen IC (2001) Fetal endocrinology and development-manipulation and adaptation to long-term nutritional and environmental challenges. Reproduction 121, 853-862.

Varvarigou A, Mantzoros CS \& Beratis NG (1999) Cord blood leptin concentrations in relation to intrauterine growth. Clin Endocrinol (Oxf) 50, 177-183.

Wasfi I, Weinstein I \& Heimberg M (1980) Increased formation of triglycerides from oleate in perfused livers from pregnant rats. Endocrinology 10, 584-596.

Wauters M, Considine RV \& van Gaal LF (2000) Human leptin: from an adipocyte hormone to an endocrine mediator. Eur $J$ Endocrinol 143, 293-311. 